\title{
Seismic Damage Propagation Prediction in Ancient Masonry Structures: an Application in the Non-Linear Range Via Numerical Models
}

\author{
P. Pineda*,1 $^{,}$M.D. Robador ${ }^{2}$ and M.A. Gil-Martí ${ }^{1}$ \\ ${ }^{1}$ Department of Continuum Mechanics and Structural Analysis, School of Architecture, University of Seville, Spain; \\ ${ }^{2}$ Department of Building Construction, School of Architecture, University of Seville, Spain
}

\begin{abstract}
Preservation of the architectural heritage placed in seismically active regions is a crucial issue. A contribution to dynamic characterization and seismic assessment of medieval masonry structures is provided in a representative single case study, the Árchez tower, located in the active seismic area of Málaga, Spain. This study follows a multidisciplinary approach, in order to identify architectural, historical and structural features. The tower exhibits high vulnerability under seismic action, mainly due to its slenderness, low shear strength, low ductility and its possible lack of effective connections among structural elements. To assess its safety, transient and incremental static analyses are performed, aimed at predicting the seismic demand as well as obtaining the expected plastic mechanisms, the distribution of damage and the performance of the building under future earthquakes. A number of three-dimensional linear and non-linear finite element models with different levels of complexity and simplifications are developed, using 3-D solid elements, 3-D beams and macro-elements. All the models assume that the masonry structure is homogeneous, and the material non-linear behaviour -including crushing and cracking- is simulated by means of different constitutive models. Comparison among the different models is discussed, in particular as predicted local and global collapse mechanisms is concerned, to evaluate the suitability, accuracy and limitations of each analysis.
\end{abstract}

Keywords: Ancient masonry structures, damage evolution, non-linear analysis, pushover analyses, seismic assessment, seismic loading, transient dynamic analyses.

\section{INTRODUCTION}

Ancient masonry structures located in seismically active areas are especially prone to suffer structural damages, owing to its geometrical, mechanical and structural features, which could lead to global or local collapse mechanisms. Dynamic assessment of historical buildings is often a complex task, being crucial to distinguish between stable damage patterns and damage evolution leading to a global collapse. Moreover, it is necessary to avoid biased structural results which invalidate the numerical analyses. Among all sources of uncertainty stemming from this kind of analysis, the seismic input, the material constitutive models, the structural model and its computation, the two last are the focus of this research.

If a comprehensive study on structural behaviour is going to be performed, accuracy and suitability of the analytical or numerical method selected and the reliability of the material constitutive model are essential issues. When an ancient structure is assessed under dynamic loading, predicting the hierarchy of failure mechanisms, and quantifying the energy absorption, as well as force redistribution, are crucial issues. Under those premises, elastic seismic analyses are not adequate and the inelastic structural response in the time domain or under static incremental loading is needed.

In this framework, as masonry slender towers exhibit high vulnerability under horizontal actions, it is critical for

*Address correspondence to this author at the Department of Continuum Mechanics and Structural Analysis, School of Architecture, University of Seville, Spain; Tel: +34652459943; E-mail: palomapineda@us.es their preservation to assess seismic safety in order to evaluate their dynamic response and, if necessary, to improve their structural strength. In fact, prevention and rehabilitation can be successfully achieved only if diagnosis of the building is carefully analyzed [1]. These structures are able to resist gravitational actions, but as they were not explicitly designed to withstand seismic loading, show particularly weakness with regard to horizontal loadings induced by a strong-motion. The high vulnerability of these constructions under horizontal actions is mostly due to the absence of adequate structural connections, which leads to overturning collapse [2] and to the mechanical deterioration of the building materials.

In this work, a contribution to seismic damage propagation prediction is provided in a single case study, the Árchez medieval tower, revealing advantages or disadvantages of different numerical analyses, under different constitutive model assumptions. This is a building of a type which represents a wide range of medieval structures built in Southern Spain. Simplified and detailed models based on the Finite Element Method, FEM, and macro-models are performed. The analyses range from static to transient nonlinear and simulation of masonry brittle behaviour is also included in numerical models. Thus, stiffness degradation as well as cracking and crushing evolution are taken into account. In addition, the effects of a previous retrofit intervention on the dynamic response, and its effect on weakness generation are also investigated.

This research aims at offering a procedure to predict damage evolution as a main step to select appropriate repair 
measures, thus developing an accurate and practical method of analysis of dynamic response in architectural heritage.

\section{HISTORICAL SURVEY}

Several researches indicate the necessity of a multidisciplinary approach to the seismic assessment of ancient masonry buildings $[3,4]$ being the historical survey the first step of this procedure.

The Árchez tower is a medieval construction located in Árchez, in the province of Málaga, Spain, and nowadays it is part of the Nuestra Señora de la Encarnación Church, which was initially erected as a mosque, Fig. (1).

Andalusian minarets form a school unique in the Islamic world for its fidelity to ancient constructions and for its innate conservatism, which maintained a broadly consistent form throughout Northern Africa and Southern Europe for over a millennium. In fact, this tower registers the highwater mark of Almohad style in western Islam. Those towerlike structures exhibit a slender shape, as can be appreciated in the mosques of Seville, Marrakesh and Rabat. Their stylistic aspects are shared with early Syrian minars, which adopted those geometrical and structural features from the earliest Syrian Christian towers [5]. Indeed, previous constructive and stylistic influences can be found from different cultures and regions. Thus, the Roman and Visigoth legacy can be observed, and many of the basic constructive techniques remained the same throughout the Islamic times in Spain. With regard to the Islamic architectural features, owing to the early incorporation into the Independent caliphate, the Spanish Islamic buildings are quite different from the construction of the centre of the empire. Notwithstanding this, the main influences from within Islam are from North Africa and Syria. North African influence was originated in the Almohad and Almoravids invasions, and that of Syria came from the Cordoban Umayyad dynasty. The Great Mosque of Cordoba was the architectural masterpiece from which Syrian influences were re-interpreted and radiated throughout the medieval Islamic world in the West.

The building materials used - stone, baked and mud bricks for walls, and wood for roofs- show also the diversity of cultural influences. The wooden roofs were usually covered with baked clay tiles, and the walls were built with ashlar masonry or coursed rubble form. Furthermore, masonry from Roman and Visigothic construction was re-used. One of the most distinctive constructive features of Spanish Islamic architectural is the use of brick in ashlar masonry. This method became a refined technique, which follows the Roman building canons [6].

The role of those constructions is crucial in the evolution of future architectural styles. Thus, the most representative features of those minars established a tradition followed in North African mosques of the XIVth century and later. In time, these designs were adopted by Spanish Christian architects in order to build church bell towers. The aforementioned characteristic features were adopted in Mudejar and Mozarabic architecture. This influence also reached the Spanish Jewish constructions and the religious building erected in America in the XVIth century.
In this historical context, the analyzed minaret was built. The minar has been dated between the XIIIth and the XIV centuries by stylistic studies [7]. This relevant tower perpetuates the outer shell of pre-Islamic Syrian towers and incorporates stylistic influences from different cultural stages. Thus, it shares structural, constructive and artistic features with different medieval Islamic towers, namely, the San Juan de los Reyes Nazarí minaret in Granada, the SidiL'alwi XIIIth minaret in Tremecen, the Sidi-Bu-Medina XIV century minar in Tremecen and the Abul-Hassan XV minar in Chella. The Árchez tower has been inscribed in the Spanish Heritage Monument Listing since 1979.

\section{GEOMETRICAL AND STRUCTURAL SURVEY}

The Árchez tower is situated in the Northeast facade of the church, being worth noting that both buildings are independent structures. The tower is of moderate size, $3.50 * 3.50$ $\mathrm{m}^{2}$ in lower plan, and it rises $16.85 \mathrm{~m}$ above the current ground level. The initial height was $14.0 \mathrm{~m}$, but when the medieval minaret was turned into a Christian campanile, an upper part was added. Its initial plan-height relation is $1 / 4$, complying with Islamic slenderness canons of this age. The facade is decorated with a band of polychrome tilework and multifoil dual blind arches at the top levels, and four rectangular panels with networks of lozenge shapes at each external wall, as can be seen in Fig. (1).

Morphologically, the minaret is divisible into three structural parts: external walls, central core and barrel vaults. The average thickness of walls is $0.50 \mathrm{~m}$, core cross-section is $1.00 * 1.00 \mathrm{~m}^{2}$ and barrel vaults cross section is $0.15 \mathrm{~m}$. The inner chamber consists of an anti-clockwise staircase covered by horizontal barrel vaults, which ascend around the square central solid core. This chamber is illuminated by narrow slits. The whole structure is built of clay bricks and irregular stones bonded with lime mortar, which were originally covered with painted plaster. The aforementioned building materials are essential in Islamic Andalusian constructions. Brick average size is $0.25 * 0.135^{*} 0.04 \mathrm{~m}^{3}$ and average lime thickness is $0.04 \mathrm{~m}$.

A careful visual survey of the structure revealed bricks and stones without bond, as well as vaults with holes. No information on the character of the foundation is available, but the structure is supposed to be embedded in the soil. In 1986, a retrofitting intervention consisting of local reconstruction of the walls, construction of a new wooden roof with tile coating and a perimeter tie beam at the top level, was performed. To conclude it is important to mention that no severe damage is observed in this building.

\section{NUMERICAL ASSESSMENT OF THE SEISMIC RE- SPONSE}

A number of three-dimensional linear and non-linear finite element models with different levels of complexity and simplifications are developed, using 3-D solid elements, 3-D beam and macro-elements. The material non-linear behaviour -including crushing and cracking- is simulated by means of different constitutive models. In order to detect structural weakness and to understand the general behaviour static and eigenvalue analyses are performed. Subsequent non-linear transient and static analyses are performed in order to evalu- 
ate the performance of the building under a future simulated ground motion.

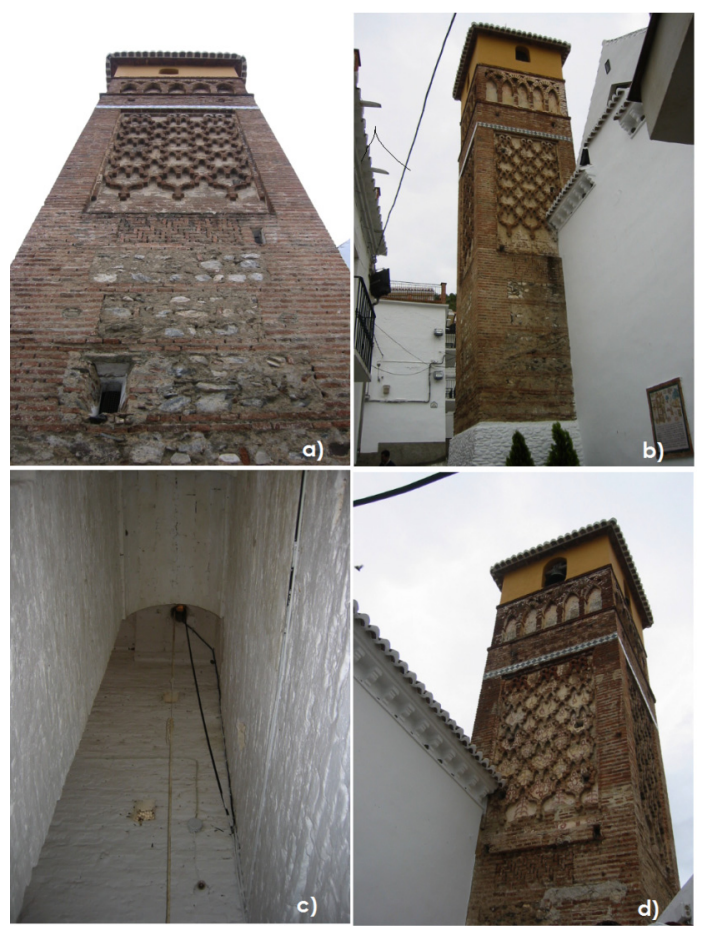

Fig. (1). (a), (b), (d)general views; (c)inside chamber.

\section{STATIC ANALYSIS WITH LINEAR AND NON- LINEAR MATERIAL}

A first static analysis is carried out focused on a detailed three-dimensional finite element model, considering accurately all the essential structural features of the "as is" building. The ANSYS finite element software is used to construct the model, and three-dimensional eight node solid elements, SOLID 45, are employed for masonry material [8]. The mesh consists of 48,964 elements, the average element size is $0.11 \mathrm{~m}$. and the wall thickness is discretized with at least four elements. This model comprises the most significant structural parts, namely real load-bearing wall thickness, openings, vaults and central core, Fig. (2). The staircase selfweight is applied on the vaults, due to its constructive features. Regarding physical material properties, results from similar buildings in the area are adopted [9]. A smeared model with homogenized properties is performed, and its linear elastic material properties are shown in Table 1. As far as boundary conditions are concerned, the base of the tower is considered as completely constrained, and following the building usages of that time, outer walls and core are directly embedded in the soil, acting as foundation.

This preliminary study provides valuable information both on global behaviour and on interaction among the structural parts. Indeed, the analysis of the structure under gravity loading yields significant data, such as stress distribution, weak elements of potential failure and displacements, Fig. (3).

From the static numerical approach, it may be observed that maximum compression level-0.36 $\mathrm{MPa}$ - is reached by the basement, as expected, whereas maximum tensile stresses $-0.17 \mathrm{MPa}-$ appear in the vaults. Furthermore, high stress concentrations are obtained in the connections among structural parts and in the openings. The compressive stresses are admissible, but as stresses higher than tensile strength are obtained, the use of non-linear material is advisable.
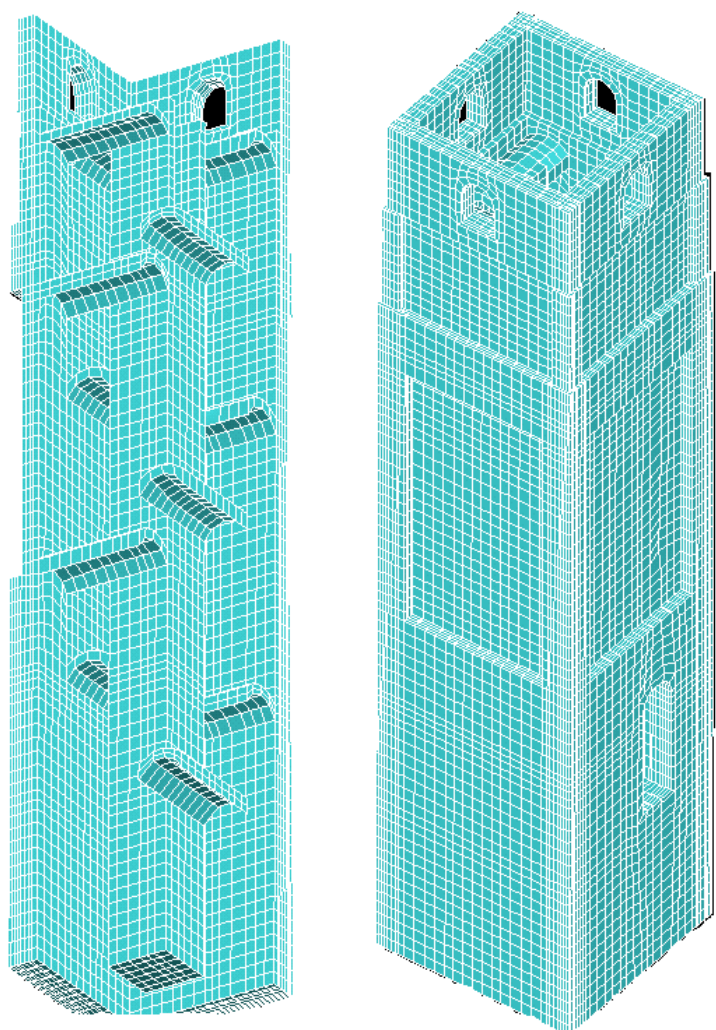

Fig. (2). Finite element model mesh: (a) inside chamber detail; (b) walls.

Table 1. Model Calibrating Parameters

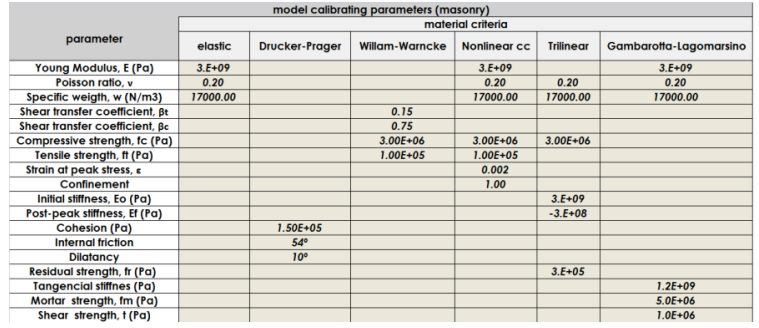

A second static analysis is performed on the same detailed three-dimensional finite element model, taking into account the material brittle behaviour by means of the Drucker-Prager perfectly plastic criterion [10] and the Willam-Warncke failure surface [11]. Those criteria provide neither stiffness degradation of brittle material caused by successive plastic deformation, nor cracks resulting from low cycle fatigue $[12,13]$. However, both theories yield accurate results on three-dimensional solid models, in particular when predicted cracking progression is concerned. Furthermore, the previous static analysis and the following non-linear analysis show that either crushing or plastic deformation due to high compressive levels are not found in the Árchez 
tower. Prior literature on masonry structural analysis $[12,14-$ 16] has used those criteria in order to determine the frontier between linear and non-linear behaviour in masonry structures.

Three-dimensional eight-noded solid isoparametric element, SOLID 65 [8], is employed to model the non-linear behaviour of bricks, stones and mortar. The element is capable of cracking in tension -in three orthogonal directionsand crushing in compression. The masonry is assumed to be initially isotropic, until either one of the tensile or the compressive strength is exceeded. When cracking occurred, it is modeled through an adjustment of material properties which treats the cracking as a "smeared band" of cracks. The stressstrain matrix is adjusted by introducing a plane of weakness in a direction normal to the crack face, and two shear transfer coefficients for open and closed cracks, $\beta_{t}=0.15$ and $\beta_{c}=0.75$ are considered. The $\beta_{t}$ represents a shear strength reduction factor for those subsequent loads which induce sliding -shear- across the crack face. If crushing occurs, the complete deterioration of the structural integrity of the material is considered, and contribution to the stiffness of an element at the integration point is ignored.

The failure criterion is defined by means of two uniaxial strengths, namely uniaxial compressive strength, $f_{c}$, and uniaxial tensile strength, $f_{t}$. A parameter variation study of results concerning the uniaxial tensile strength as a percentage of the compressive strength is performed. The values thus selected are consistent with the present conservation state. With regard to the Drucker-Prager parameters, the expressions proposed by Lourenço [17] are considered, as shown in Table $\mathbf{1 .}$

The results obtained are consistent with the linear analysis. Maximum compressive stresses $-0.36 \mathrm{MPa}$ - were reached by the basement, as expected. Maximum tensile stresses $-0.11 \mathrm{MPa}$ - appear in the vaults, door and rectangular panel perimeters. The compressive stresses are admissible, but as the elastic analysis show that stresses higher than tensile strength are obtained, the use of non-linear material is advisable. Furthermore, those results allow to conclude that connections between vaults and walls are confirmed to be a vulnerable part of the building. With regard to displacements, the maximum horizontal values are reached by the vaults and the core at the top level.

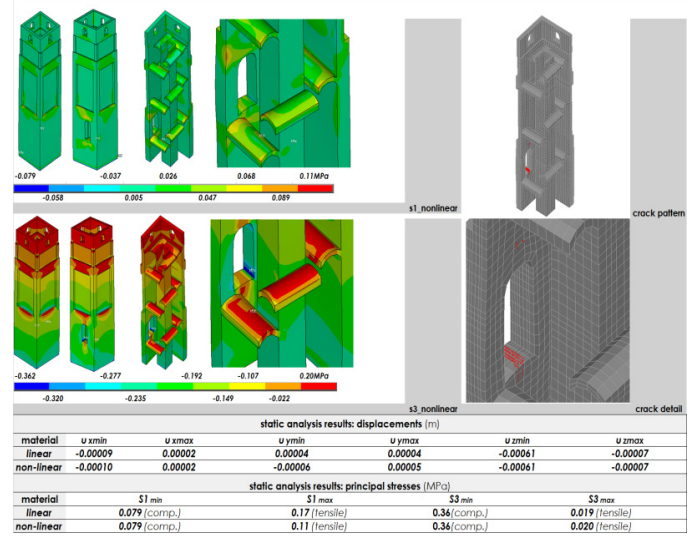

Fig. (3). Static analysis results with linear and non-linear material.

\section{MODAL ANALYSIS}

A modal analysis is computed on this detailed model, in order to obtain the dynamic properties -natural frequencies, $\omega_{n}$, and modal shapes, $\zeta_{n}$ - and to serve as a starting point for the transient dynamic analysis. Damping is not taken into account. The sum of the effective modal masses for the first 25 modes is more than the $90 \%$ of the total mass and each mode has an effective mass greater than $5 \%$ of the total. The main effective masses are shown in Table 2 . The significant modal shapes are provided in Fig. (4).

Table 2. Modal Participating Mass Ratios for Each Principal Direction

\begin{tabular}{|c|c|c|c|c|c|c|c|}
\hline & & in effec & five masse & ez & wer & & \\
\hline \multirow{2}{*}{ mode No } & \multirow[t]{2}{*}{ Period $\mathrm{T}(\mathrm{s})$} & \multicolumn{2}{|c|}{$x$-direction } & \multicolumn{2}{|c|}{$y$-direction } & \multicolumn{2}{|c|}{ z-direction } \\
\hline & & Meff (\%) & $\Sigma$ Meff (\%) & Meff (\%) & $\Sigma$ Meff (\%) & Meff (\%) & $\Sigma$ Meff $(\%)$ \\
\hline 1 & 0.265 & 40.201 & 40.201 & 18.035 & 18.035 & 0.000 & 0.000 \\
\hline 2 & 0.264 & 17.943 & 58.144 & 41.000 & 59.035 & 0.000 & 0.000 \\
\hline 4 & 0.066 & 0.700 & 58.868 & 20.588 & 80.169 & 0.000 & 0.001 \\
\hline 5 & 0.064 & 22.615 & 81.483 & 0.776 & 80.944 & 0.003 & 0.004 \\
\hline 6 & 0.043 & 0.000 & 81.484 & 0.000 & 80.944 & 76.379 & 76.383 \\
\hline 8 & 0.033 & 0.423 & 82.336 & 5.246 & 86.303 & 0.000 & 76.384 \\
\hline 9 & 0.033 & 5.147 & 87.484 & 0.436 & 86.739 & 0.006 & 76.390 \\
\hline 16 & 0.024 & 1.297 & 89.220 & 0.006 & 88.128 & 0.000 & 76.806 \\
\hline 18 & 0.023 & 0.094 & 89.607 & 1.250 & 89.384 & 0.004 & 76.814 \\
\hline
\end{tabular}

From the eigenvalue analysis results, it may be concluded that the first four modal shapes provide the highest mass contribution, and all of them involves global bending. Those shapes are characterized by a high global stiffness and a monolithic behaviour among vaults, central core and walls. The third modal shape displays torsional response, and, when higher shapes are analyzed, weak collaboration among the different structural parts is revealed, and significant outof-plane deformations are observed. It is worth to note that at higher frequencies the upper parts of the tower seem to be vulnerable.

The results obtained are consistent with the structural type, as it is characterized by two stiff elements -perimeter walls and core- connected by more flexible elements -barrel vaults-. Besides, as can be observed in Fig. (5) and (6), the 1 st and the 2 nd periods are located in the constant branch of the horizontal response spectrum.

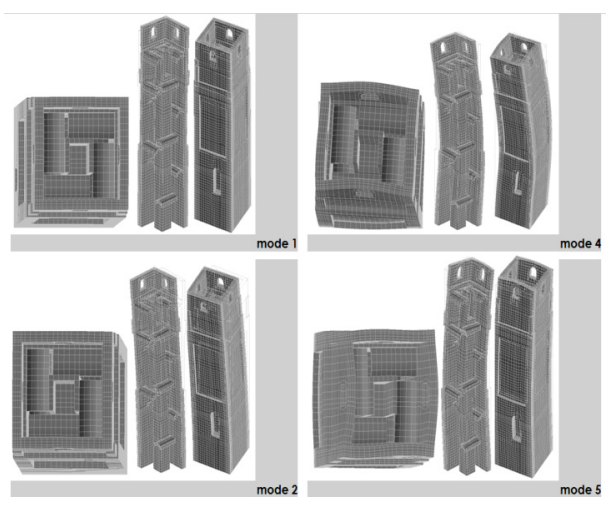

Fig. (4). Modal shapes.

\section{SEISMIC ANALYSIS}

The application of non-linear procedures to medieval masonry towers needs to overcome several issues, which are generally less relevant for other types of buildings. Some of 
the commonly accepted hypotheses, such as the rigid floor assumption and their consequences, are not valid in these studies. In order to obtain reliable and accurate damage evolution results, the inelastic structural behaviour must be considered. Moreover, as both flexural and shear resisting mechanisms may be activated under seismic base excitation, the numerical model should allow the activation of the aforementioned mechanisms.

A number of dynamic and incremental analyses are performed in order to predict nonlinear inelastic response of the "as is" tower under future seismic loading, by means of simplified and detailed numerical models. Simplified 3-D beam models allow to calibrate the non-linear response of the detailed model, and to control numerical instabilities introduced by the crack opening phenomena. All the models assume that the masonry structure is homogeneous and different constitutive models are used in order to consider the material non-linear behaviour -including crushing and cracking. These analyses yield significant information on the local and global collapse mechanism predictions.

\section{SEISMIC INPUT}

The Árchez tower is placed in the province of Málaga, at Southern Spain, the zone with the highest seismic hazard in the Iberian Peninsula, where the value of the peak ground acceleration is $0.21 \mathrm{~g}$ according to the Spanish Seismic Standard [18].

On a time scale, the regional seismicity is characterized by a high microseismic activity rate for magnitudes lesser than 4.5 , and less frequent earthquakes of magnitudes between 4.5 and 6.0 which generated important damages in the past in the Granada basin and Málaga [19]. Historical surveys show that the major strong-motion in the area was the Andalusia Earthquake of 1884, also known as the Arenas del Rey Earthquake. A surface-wave magnitude, $M_{s}$, value of 6.5 \pm 0.6 has been assigned to this destructive earthquake [20].

Modelling of seismic input is achieved by means of artificial waveforms. These artificial accelerograms are generated following the proposed method by Gasparini and Vanmarcke [21] in order to match a target response spectrum in a large range of periods. Although these signals may lead to accelerograms with unrealistic energy content (they do not reflect the real phasing of seismic waves and cycles of motion), they may be useful for few recorded motion scenarios. Moreover, as they are calculated in a relatively fast way, they would be useful for emergency assessment within the nonlinear range. Following this procedure, seven synthetic

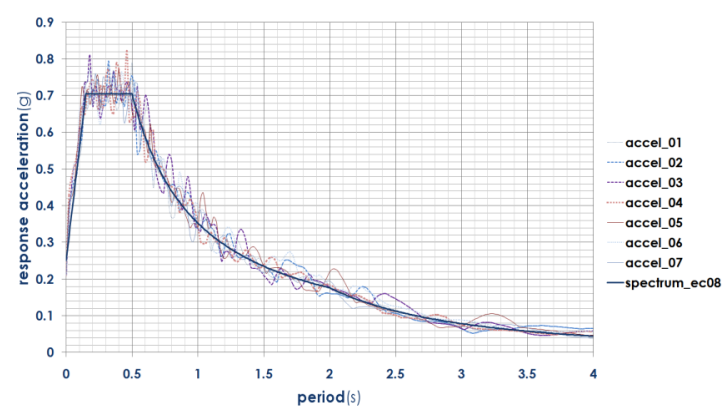

Fig. (5). Horizontal response spectra.

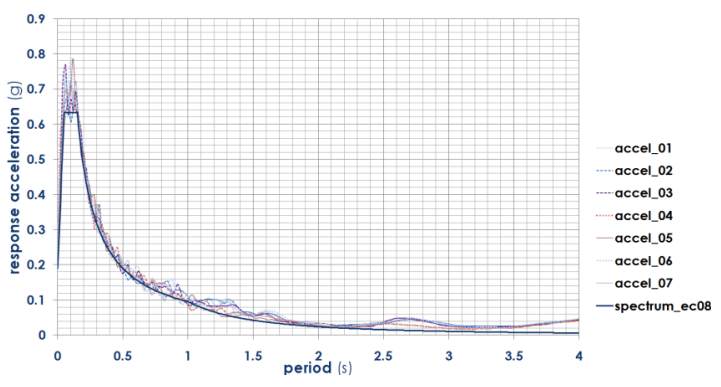

Fig. (6). Vertical response spectra.

accelerograms compatible with the Eurocode 8 [22] horizontal and vertical design spectra are generated, Figs. $(5,6)$ and (7). The type 1 elastic response parameters, for a ground type $\mathrm{B}$, are adopted. The stationary part duration is equal to $10 \mathrm{~s}$ and the total duration is equal to $25 \mathrm{~s}$.
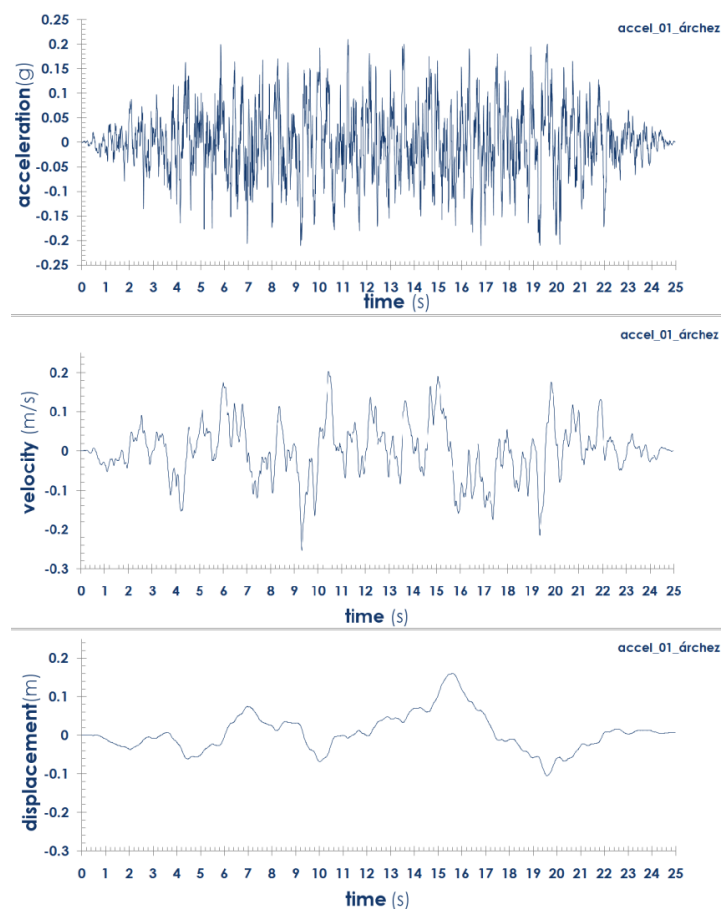

Fig. (7). Artificial waveforms.

\section{NON-LINEAR DYNAMIC AND PUSHOVER ANALY- SES}

In a first step, non-linear dynamic analyses are carried out on simplified beam models. These models allow to predict the nonlinear inelastic seismic response of the tower providing an upper limit response- and to calibrate the detailed model. The direct integration of the motion equations was accomplished using the Newmark algorithm [23]. The ANSYS and SeismoStruct F.E. softwares are used to compute the response. The BEAM4 ANSYS [8] element and the 3-D Inelastic Frame beam-column SeismoStruct [24] element are used. Cantilever beam models, comprised of the central solid core where the node position is the same that the vaults position, are performed in order to obtain an upper 
limit response. Other research works have considered structural parts as perfectly merged in beams models in order to obtain lower limit response [25]. Modelling of non-linear material behaviour is achieved by means of different constitutive models, namely, an uniaxial nonlinear constant confinement model, and a simplified uniaxial trilinear concrete model.

The former follows the constitutive relationship proposed by Mander and co-workers [26] and the cylic rules proposed by Martinez-Rueda and Elnashai [27]. This is a cyclic stressstrain model for both confined and unconfined brittle materials, and it is able to provide a good estimation of the cyclic response of structures dominated by flexure and axial force under static and dynamic conditions. The specific model calibrating parameters used to fully describe the mechanical characteristics of this model were: compressive strength $\mathrm{fc}$, tensile strength $\mathrm{ft}$, strain at peak stress $\varepsilon$, confinement factor $k_{c}$, specific weight $w$, Young modulus $E$, and Poisson ratio $v$, see Table 1. This approach allowed to cope with the structural response under cyclic loading, taking into account inelastic strain and degradation of strength and stiffness.

The latter model assumes no resistance to tension and features a residual strength plateau. The specific model calibrating parameters used to describe the mechanical material properties were: compressive strength $f_{c l}$, initial stiffness $E_{l}$, post-peak stiffness $E_{2}$, residual strength $f_{c 2}$, specific weight $w$, Young modulus $E$, and Poisson ratio $v$, see Table 1.

A Rayleigh model for damping is assumed, that is:

$$
c=a_{0} m+a_{1} k ; \quad a_{0}=\zeta \frac{2 \omega_{i} \omega_{j}}{\omega_{i}+\omega_{j}} \quad a_{1}=\zeta \frac{2}{\omega_{i}+\omega_{j}}
$$

where $c, m$ and $k$ are the damping, mass and stiffness matrices, respectively. The two modes $i$ and $j$ were assumed to have the same damping ratio equal to $3 \%$. That ratio is a recommended value for unreinforced masonry structures [28].The modes considered are the first one and the second one, as they contributed significantly to the response. The first natural frequency $\omega_{1}$ was equal to $3.95 \mathrm{rad} / \mathrm{sec}$ and the second natural frequency $\omega_{2}$ was equal to $25.1 \mathrm{rad} / \mathrm{sec}$. According to (1) the coefficients $a_{0}$ equal to 0.20 and a1 equal to 0.002 are obtained.

Three simultaneously acting synthetic accelerograms are the input at the basement. The time-dependent structural response is obtained from 7 nonlinear time-history analyses, following the component combinations proposed by EC8 [22].

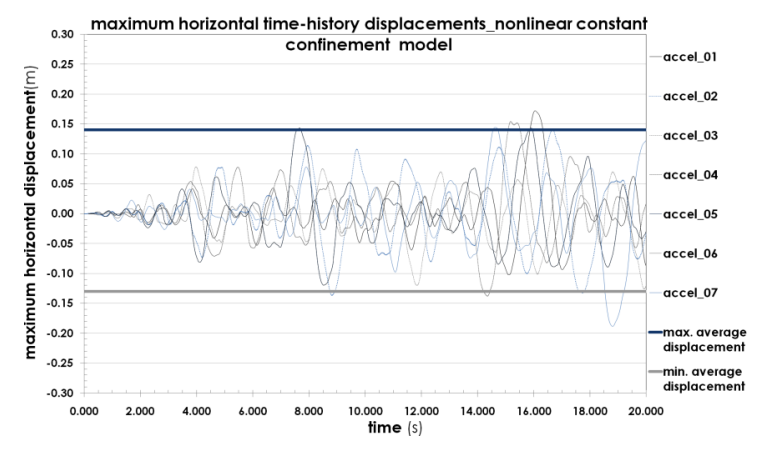

Fig. (8). Time-history results nonlinear confinement model.

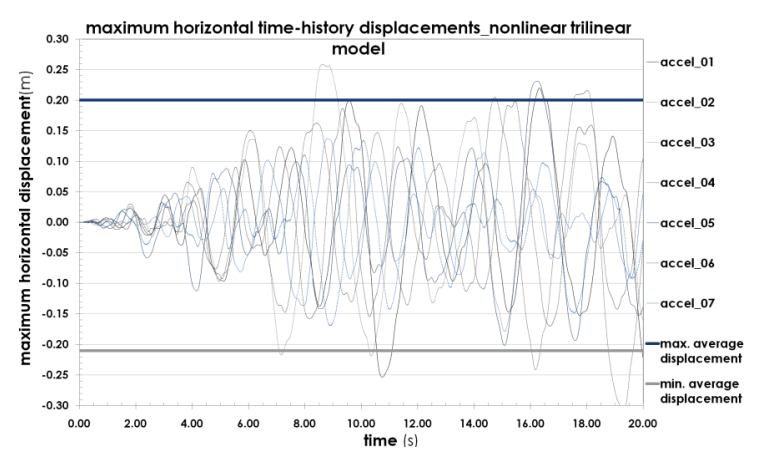

Fig. (9). Time-history results trilinear model

Those simplified models provide relevant information when global collapse mechanisms, such us the tower overturning, are analyzed. The solid central core is safe if, for each time step the response eccentricity is minor than the eccentricity of the normal force producing the over-turning. After analysing efforts and displacements, it may be concluded that the tower is stable under this earthquake loading, Figs. (8) and (9).

In order to complete the dynamic survey, non-linear static analyses are performed according to EC 8 [22], including the effects of the retrofitting intervention. A discrete 3-D macro-element model is calculated, following the theories proposed by Gambarotta and Lagomarsino [29] and using the 3-MURI [30] and TREMURI [31] softwares. Axial deformability is concentrated in the two extremes of the macroelement, which are infinitely rigid to shearing actions. The tangential deformability is situated in the central body, which is non-deformable under axial and flexion. Walls are schematized as a frame, where the resistant elements (piers and spandrel beams) and the rigid nodes are assembled. The vault finite element is defined with axial rigidity, but without bending rigidity. The cyclical evolution of the rigidity degradation is considered. Model calibrating parameters are shown in Table 1.

This study involves a comparison between the capacity curves found and the displacement required by the Code [22]. The capacity curve shows the relationship between maximum displacement and shear at the base. Each curve is associated to its bilinear simplification -equal energy criterion- by means a SDOF elastic perfectly-plastic approximation. Two types of load conditions are considered, namely, mass proportional distribution, and 1st mode proportional. Two different structures are analyzed, the "no-strengthened" model and the "as is" model (m04 in Fig. 10). The former represents the actual structural state before the 1986 retrofitting intervention ( $\mathrm{m} 01$ in Fig. 10), and the latter considers the present state of conservation, including the 1986 strength measures, that is, the local reconstruction of the walls ( $\mathrm{m02}$ in Fig. 10) and the construction of a new wooden roof with tile coating and a perimeter tie beam at the top level ( $\mathrm{m} 03$ in Fig. 10). In both models, Ultimate Limit State $-U L S$ - and Damage Limit State $-D L S$ - are studied. In those analyses, $D_{\max }$ is the maximum displacement requested by the code identified in the elastic spectrum at $U L S, D_{u}$ is the maximum displacement displayed by the structure in $U L S, D S L_{D \max }$ is 
the maximum displacement requested by the code, assuming $a_{g}(D L S)$ and $D_{d}$ is the maximum displacement at $D L S$.
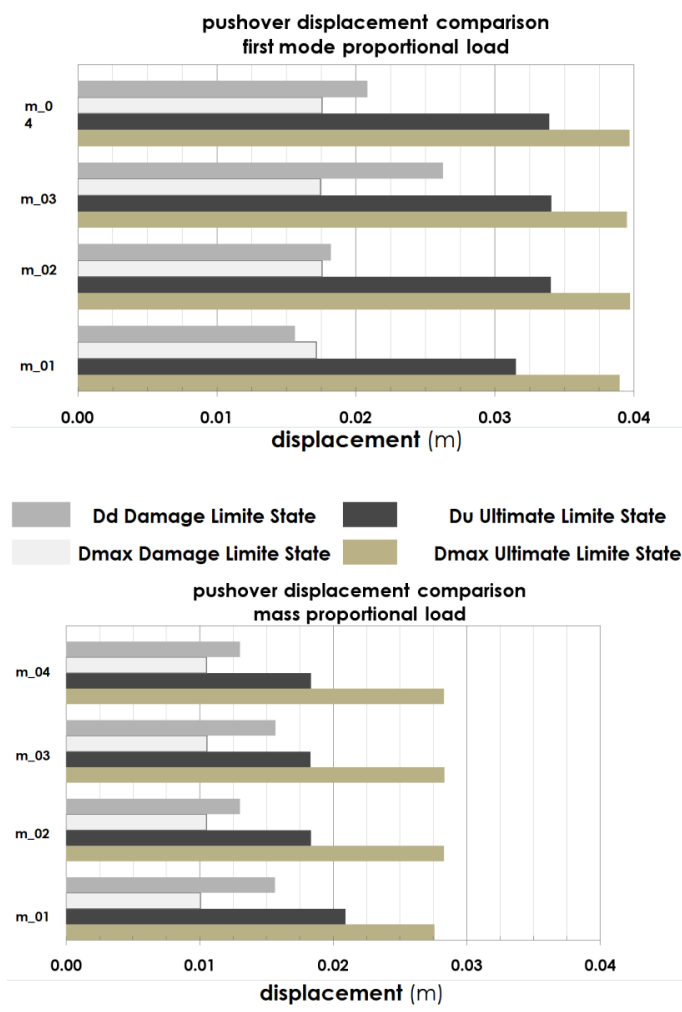

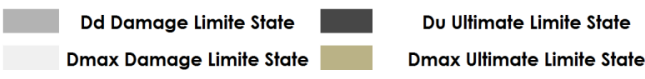

Fig. (10). Pushover displacement comparison under different structural improvements.

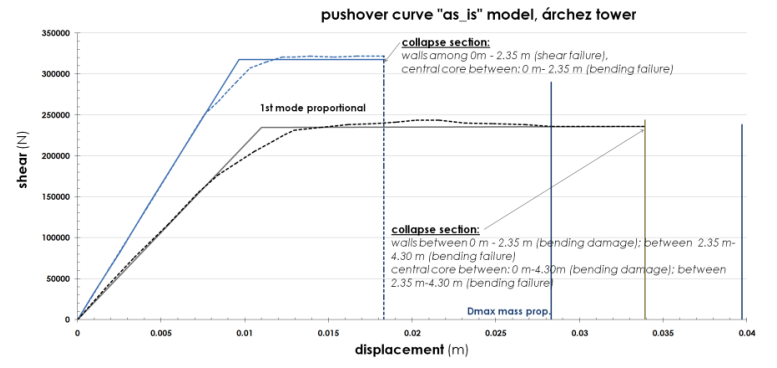

Fig. (11). Pushover curve "as is" model.

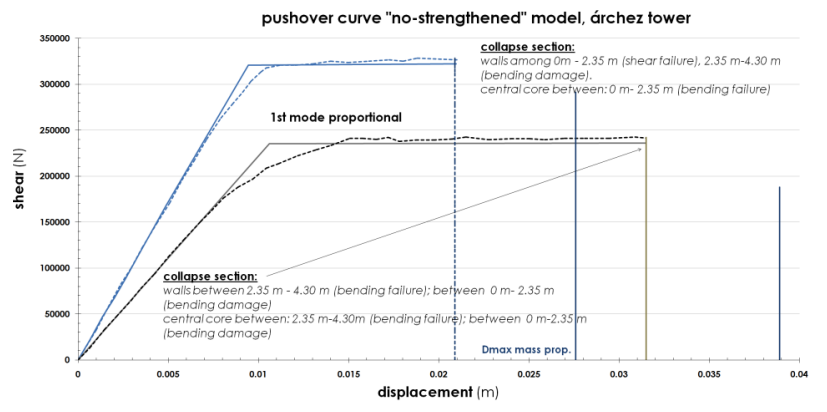

Fig. (12). Pushover curve "no-strengthened" model.
The pushover analyses show rather different failure mechanism, depending on the load distribution. Thus, in the "as is" curve, Fig. (11), the uniform distribution causes a "first floor soft storey" mechanism-shear failure- in the outside walls, as well as bending failure in the lower plan of the core. This load pattern describes the behaviour of a building under extensive damage. Meanwhile, the modal distribution -which represents the structural dynamic amplification- induces distributed bending damage and failure in upper levels. The strength measures improve the response under modal distribution, but as far as the mass proportional loading is concerned the damaged areas are reduced but $D_{u}$ increases. The pushover curve of the "no-strengthened" model, Fig. (12), shows more extensive damages under mass proportional loading, as also bending damage is observed in the walls. After comparing both curves, Figs. (11) and (12), it may be concluded that the retrofitting intervention improves the structural response under dynamic loading. In order to evaluate the reliability of the prediction and evaluate the actual collapse mechanism, the pushover results for the central core are compared with that of transient analyses, as can be observed in Fig. (13) $\left(m_{1}\right.$ and $m_{2}$ are the constant confinement and trilinear models respectively), as well as the response under different structural improvements, Fig. (10). The non-linear static procedures yield more conservative results than the transient analyses, except for the maximum displacement requested at $U L S$ under 1st mode proportional loading. It is worth to mention that the detailed 3D FE model features a $15 \%$ higher stiffness than the macro-model.

From the performed analyses, it is concluded that lateral load distribution does greatly affect the pushover curves. The more accurate load pattern is not always evident in this kind of buildings. Unlike many structures where mass can be realistically lumped at the diaphragms, in this tower the main proportion of the total mass is distributed among the central solid core and the external walls. Neither the flexible wooden floors, nor the vaults, provide rigid- diaphragm constrain at their level, so lumping the mass at that levels would preclude adequate estimation of modal shapes and mass participation.

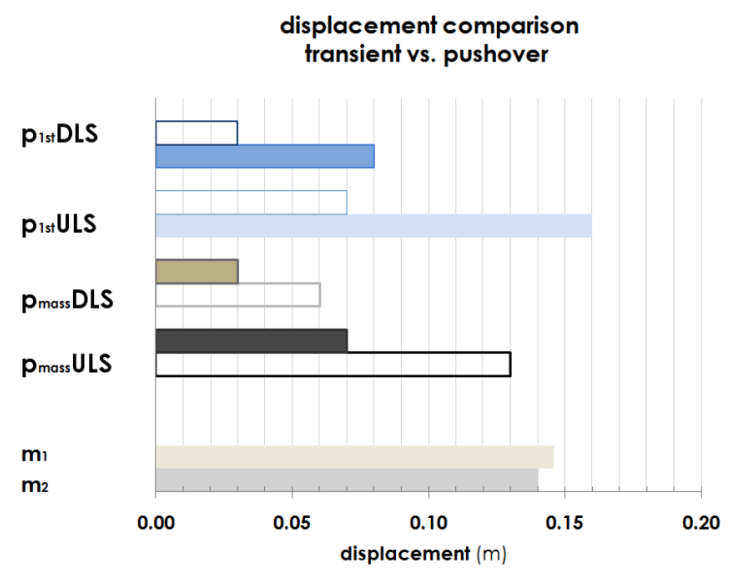

Fig. (13). Displacement comparison transient vs. pushover at the central core.

In a last step, transient analyses are performed on the detailed 3-D solid "as is" model. A Rayleigh model for damp- 
ing-according to the previous modal analysis-was assumed, and the coefficients $a_{0}$ equal to 1.14 and $a_{l}$ equal to 0.0005 were applied. Two different materials were considered, namely the linear elastic material and the Drucker-Prager Willam-Warncke non-linear material. The results obtained show that the low tensile strength exhibited by masonry, leads to a higher cracking pattern than the static approach (Fig. 14), and the shear stresses are also higher. In spite of the dynamic input no global collapse is expected, although numerous local cracks appear.

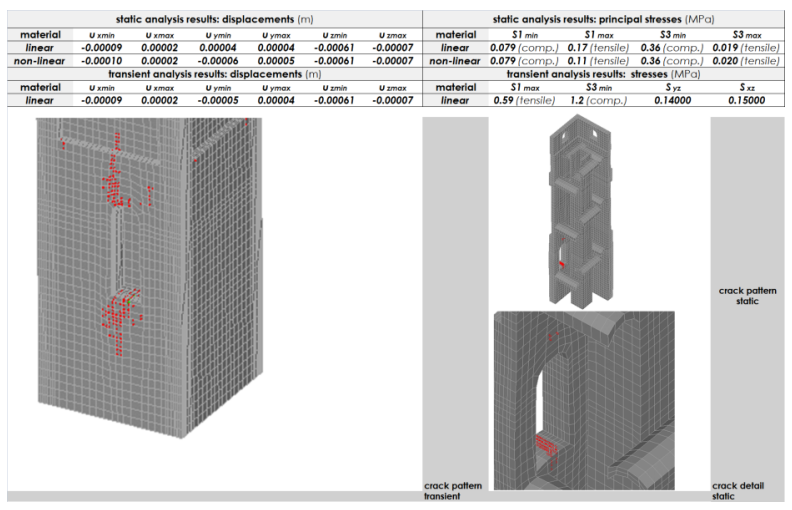

Fig. (14). Transient results versus static results

\section{CONCLUSIONS}

The Árchez medieval tower has been numerically analyzed in order to assess its structural response under seismic loading. Transient and incremental static analyses pushover- are performed, aimed at obtaining the expected damages and the performance of the building under future earthquakes.

As far as the seismic transient analyses are concerned, it may be stated that the Drucker-Prager perfectly plastic criterion and the Willam-Warncke failure surface, are valuable tools to predict cracking progression when neither crushing nor high plastic deformation due to high compressive are expected. The simplified models allow to determine the upper boundary response- i.e. the tower over-turning-, taking into account the response under cyclic loading. Under those seismic analyses, the structures exhibit severe local damages -cracks- but no collapse is expected.

However, the pushover analyses yield global collapseshear or flexural failure mechanism-. These unrealistic responses are obtained owing to the higher mode effects, and the modal variations resulting from inelastic behaviour. The load distribution also introduces important uncertainties.

The performed analyses allow determining the distribution of predicted cracking and a possible global collapse mechanism. The aforementioned methodology might be useful in order to assess safety and to improve seismic resistance of this and other similar cultural heritage buildings.

\section{ACKNOWLEDGEMENTS}

This work has been funded by the Ministerio de Ciencia e Innovación, under the project BIA2009-12618. The authors would like to gratefully thank to the Delegación de Patrimo- nio of Málaga, for providing graphical and historical information on the Árchez tower.

\section{REFERENCES}

[1] L. Binda, A. Saisi, and C. Tiraboschi, "Investigation Procedures for the Diagnosis of Historic Masonries", Construction and Building Materials, vol. 14, pp. 199-34, 2000.

[2] P. B. Lourenço, and J. A. Roque, "Simplified Indexes for the Seismic Vulnerability of Ancient Masonry Buildings", Construction and Building Materials, vol. 20, pp. 200-8, 2006.

[3] A. Giuffrè, Sicurezza e Conservazione dei Centri Storici: Il Caso Ortigia. Bari, Italy, Editori Laterza, 1993.

[4] F. Casarin, and C. Modena, "Seismic Assessment of Complex Historical Buildings: Application to Reggio Emilia Cathedral, Italy", International Journal of Architectural Heritage, Vol. 2, pp. 304-23, 2009.

[5] J. Bloom, Minaret: Symbol of Islam, Oxford Studies in Islamic Art, Oxford : Oxford University Press, 1989.

[6] A. Petersen, Dictionary of Islamic Architecture, London : Routledge, 1999.

[7] M. D. Aguilar García, "Dos Alminares Malagueños”, in Proceedings of XXIII Congreso Internacional de Historia del Arte, (in Spanish), 1973, vol. 2, pp. 15-6.

[8] ANSYS, “ANSYS Manual SET", Canonsburg : ANSYS Inc., Southpoint, 275 Technology Drive, 1998.

[9] A. B. Padura, "Estudio de las Cimentaciones de Edificios Históricos en la Provincia de Sevilla: Siglo XII al XVI", Ph. D thesis,(in Spanish), Universidad de Sevilla, 2001.

[10] D. C. Drucker, and W. Prager, "Soil mechanics and plastic analysis or limit design", Quarterly of Applied Mathematics, vol. 10, pp. 157-16, 1952.

[11] K. J. Willam, and E. D. Warncke, "Constitutive Model for the Triaxial Behaviour of Concrete", in Proceedings of the International Association for Bridge and Structural Engineering, ISMES, 1975.

[12] F. J. Pallarés, A. Agüero, and S. Ivorra, "A Comparison of Different Failure Criteria in a Numerical Seismic Assessment of an Industrial Brickwork Chimney", Materials and Structures, vol. 42, pp. 213-13, 2009.

[13] D. V. Oliveira, and P. B. Lourenço, "Implementation and validation of a constitutive model for the cyclic behaviour of interface elements", Computers and Structures, vol. 82, pp. 1451-10, 2004.

[14] P. J. Fanning, and T. E. Boothby, "Three-Dimensional Modelling and Full-Scale Testing of Stone Arch Bridges", Computers and Structures, vol. 79, pp. 2645-17, 2001.

[15] G. Bartoli, M. Betti, P. Spinelli, and B. Tordini, "An "Innovative” Procedure for Assessing the Seismic Capacity of Historical Tall Buildings: The "Torre Grossa" Masonry Tower", in Proceedings of Structural Analysis of Historical Constructions Conference, New Delhi : P.B. Lourenço, P. Roca, C.Modena; S. Agrawal (Eds), 2006.

[16] M. Betti, and A. Vignoli, "Assessment of seismic resistance of a basilica-type church under earthquake loading: Modelling and analysis", Advances in Engineering Software, vol. 39, no. 4, pp. 258283, 2007.

[17] P. B. Lourenço, "Computational Strategies for Masonry Structures", $\mathrm{Ph}$. D. thesis, University of Delft, Delft, The Netherlands, 1996.

[18] NCSE-02. Norma de Construcción Sismorresistente: Parte general y edificación (NCSE-02). Madrid : Dirección General del Instituto Geográfico Nacional: Ministerio de Fomento. Centro de Publicaciones, National Code, 2004;.p. 94.

[19] J. Morales, B. Benito, and M. Luján, "Expected Ground Motion in the South-East of Spain Due to an Earthquake in the Epicentral Area of the 191 Adra Earthquake", Journal of Seismology, vol. 7, pp. 175-17, 2003.

[20] C. L. Casado, S. Molina, J. J. Giner, and J. Delgado, "MagnitudeIntensity Relationships in the Ibero-Magrebhian Region", Natural Hazards, vol. 22, pp. 271-26, 2000.

[21] D. A. Gasparini, and E. H. Vanmarke, Simulated Earthquake Motions Compatible with Prescribed Response Spectra, Department of Civil Engineering, Massachusetts Institute of Technology -MIT-, 1976.

[22] EC-8. CEN. Eurocode8: Design of structures for earthquake resistance. Part 1: general rules, seismic actions and rules for buil- 
dings. Final draft prEN1998, Brussels: European Committee for Standardization, 2003.

[23] N. M. Newmark, "A Method of Computation for Structural Dynamics. EM3", Journal of the Engineering Mechanics Division, $A S C E$, vol. 85, pp. 67-27, 1959.

[24] SeismoStruct, "SeismStruct, a Computer Program for Static and Dynamic Nonlinear Analysis of Framed Structures", 2007.

[25] Eu-Ind, Project, "Benchmarking on the Seismic Behaviour of the Qutb Minar", Asia-wide Programme: EU-IND Economic Cross Cultural Programme, Universidade do Minho, Portugal, 2006.

[26] J. B. Mander, M. J. N. Priestley, and R. Park, "Theoretical stressstrain model for confined concrete", Journal of Structural Engineering, vol. 114, pp. 1804-22, 1988.
[27] J. E. Martínez-Rueda, and A. S. Elnashai, "Confined concrete model under cyclic load", Materials and Structures, vol. 30, pp. $139-8,1997$.

[28] A. K. Chopra, Dynamics of structures: Theory and Applications to Earthquake Engineering, New Jersey: Prentice-Hall, 1995.

[29] L. Gambarotta, and S. Lagomarsino, "Damage models for the seismic response of brick masonry shear walls, Part II: the continuum model and its applications", Earthquake Engineering and Structural Dynamics, vol. 26, no. 4, pp. 441-462, 1997.

[30] TreMuri, "TreMuri Seismic Analysis Program for 3D Masonry Buildings", versione 1.7.34, 2011.

[31] 3MURI, "3 MURI Seismic Analysis Program for 3D Masonry Buildings", S.T.A DATA, 2008.

Received: June 15, 2011

Revised: August 25, 2011

Accepted: August 30, 2011

(C) Pineda et al.; Licensee Bentham Open.

This is an open access article licensed under the terms of the Creative Commons Attribution Non-Commercial License (http://creativecommons.org/licenses/by-nc/3.0/) which permits unrestricted, non-commercial use, distribution and reproduction in any medium, provided the work is properly cited. 